\title{
Factors associated with patient-reported experiences and outcomes of substance use disorder treatment in Cape Town, South Africa
}

Bronwyn Myers ${ }^{1,2,3^{*}}$ (D) J. Randy Koch ${ }^{4}$, Kim Johnson $^{2}$ and Nadine Harker ${ }^{2,5}$

\begin{abstract}
Background: Interventions are needed to improve the quality of South Africa's substance use disorder (SUD) treatment system. This study aimed to identify factors associated with patient-reported suboptimal access, quality, and outcomes of SUD treatment to guide the design of targeted quality improvement initiatives.
\end{abstract}

Method: We analysed clinical record and patient survey data routinely collected by SUD services in the Western Cape Province, South Africa. The sample included 1097 treatment episodes, representing 32\% of all episodes in 2019. Using multivariate logistic regression, we modelled socio-demographic, substance use and treatment correlates of patientreported suboptimal access to, quality and outcomes of SUD treatment.

Results: Overall, 37.9\% of patients reported substantial difficulties in accessing treatment, 28.8\% reported suboptimal quality treatment, and $31.1 \%$ reported suboptimal SUD outcomes. The odds of reporting poor access were elevated for patients identifying as Black/African, in residential treatment, with comorbid mental health problems, and longer histories of substance use. Length of substance use, comorbid mental health problems, and prior SUD treatment were associated with greater likelihood of reporting suboptimal quality treatment. Patients with comorbid mental health problems, polysubstance use, who did not complete treatment, and who perceived treatment to be of poor quality were more likely to report suboptimal outcomes.

Conclusion: This study is among the first to use patient-reported experiences and outcome measures to identify targets for SUD treatment improvement. Findings suggest substantial room to improve South African SUD treatment services, with targeted efforts needed to reduce disparities in outcomes for patients of Black/African descent, for those with comorbid mental health problems, and for patients who have chronic substance use difficulties. Interventions to enhance the relevance, appropriateness, and acceptability of SUD services for these patient sub-groups are needed to improve system performance.

Keywords: Treatment quality, Access, Substance use outcomes, Patient-reported outcome measure (PROM), Patientreported experience measures (PREM), Low-and middle-income country, Quality improvement

*Correspondence: bronwyn.myers-franchi@curtin.edu.au

${ }^{1}$ Curtin enAble Institute, Faculty of Health Sciences, Curtin University, Kent Street, Bentley, WA 6102, Australia

Full list of author information is available at the end of the article

\begin{abstract}
Background
While untreated substance use disorders (SUD) contribute substantially to the global burden of disease $[1,2]$, access to evidence-based SUD treatment can diminish this risk for poor health. Accordingly, improving SUD treatment provision is included in the United Nations' Sustainable Development Goals for 2030 [3]. However, treatment availability remains severely
\end{abstract} original author(s) and the source, provide a link to the Creative Commons licence, and indicate if changes were made. The images or other third party material in this article are included in the article's Creative Commons licence, unless indicated otherwise in a credit line to the material. If material is not included in the article's Creative Commons licence and your intended use is not permitted by statutory regulation or exceeds the permitted use, you will need to obtain permission directly from the copyright holder. To view a copy of this licence, visit http://creativecommons.org/licenses/by/4.0/. The Creative Commons Public Domain Dedication waiver (http://creativecommons.org/publicdomain/zero/1.0/) applies to the data made available in this article, unless otherwise stated in a credit line to the data. 
constrained in South Africa, a country where there is a high prevalence of substance use (SU) and SUDs [4, 5].

Although demographic data on SU are limited in South Africa, nationally $10.3 \%$ of the adult population (15 years and older) are estimated to consume alcohol at harmful levels (16.5\% of men and $4.6 \%$ of women) and $8.6 \%$ (13.3\% of men and $4.1 \%$ of women) are estimated to use illicit drugs [4]. In this context, illicit drug use is mainly driven by cannabis, followed by Mandrax (methaqualone), amphetamine-type stimulants such as methamphetamine, and opiates $[4,5]$. Evidence further suggests that a substantial proportion (13.3\%) of South Africans meet diagnostic criteria for a SUD [6], with alcohol use disorder being the most common type of SUD experienced [7]. Given these estimates, it is not surprising that South Africa's burden of disease attributable to alcohol is among the highest in the world, accounting for approximately 3013 disability adjusted life years (DALYS, 95\% UI: 2409-3610) per 100000 people. Although the drug-attributable disease burden is lower than that of alcohol, it is still within the severe range, accounting for an estimated 572 DALYS (UI 471-705) per 100000 people [8].

Despite the prevalence of SUDs in this setting $[5,6]$, treatment availability is limited with less than $5 \%$ of individuals struggling with SUDs ever accessing treatment $[9,10]$. The structural and systemic factors that contribute to this treatment gap are well documented. These include treatment infrastructure constraints, with South Africa's SUD treatment system limited to 86 treatment sites that provide about 20,000 outpatient and residential treatment episodes annually $[11,12]$. The bulk of these services are in the Western Cape province, where the prevalence of SUDs is substantially higher (20.6\%) than the national average [6]. Not-for -profit organizations (funded wholly or in part by block grants provided by the Department of Social Development) and free state-managed services account for most of the treatment episodes $[11,13]$. While there is a private-for-profit treatment sector, this is only available to the small number of South Africans with private medical insurance or who can afford to pay for these services [13]. Regardless of funding source, SUD treatment is largely non-specific (targeting all types of SUDs) and behavioral in nature [5], with pharmacotherapy only available to individuals who can afford out-of-pocket payments for medication [14]. Together with human resource shortages, these treatment infrastructure constraints contribute to high patient caseloads, long waiting periods for treatment and geographic access barriers [15-17]. Despite recent investments in additional state-funded evidence-based SUD services $[18,19]$ and workforce development initiatives $[17,20]$, access to SUD treatment remains limited.
In this context of scarce treatment resources, every opportunity for SUD treatment requires optimisation through providing appropriate and effective care [21-23]. Reports that only $2.3 \%( \pm 1 \%)$ of South Africans with a past year SUD accessed minimally adequate treatment [24] coupled with patient concerns about the effectiveness of available services [25-27] highlight the need to improve the quality of South Africa's SUD treatment offering.

System-level data on access to and quality of treatment are needed to guide SUD treatment system improvement. While the South African Community Epidemiology Network on Drug Use (SACENDU) has monitored patterns of SUD treatment utilisation for more than 25 years [11, 28], systems-level data on patient experiences of care have rarely been collected $[29,30]$. This is a critical gap to address as patients' perspectives on the SUD treatment experience are likely to influence their engagement in and completion of SUD treatment, which are important predictors of SUD treatment outcomes [31-33]. Further, patients can offer unique insights from their own lived experience into how SUD services can be improved to better meet the needs of other patients [34, 35]. Patients and provider perspectives on necessary components of quality SUD treatment often differ [35], and therefore obtaining the patient perspective on what works in SUD treatment is necessary to guide initiatives aimed at improving the patient's experience and outcomes of SUD treatment.

Several SUD-specific patient-reported experience measures (PREMs) and patient-reported outcome measures (PROMs) now exist to support the routine collection of these data (see Ref. [31, 34, 36, 37]) including measures developed and validated for the South African treatment context $[30,38]$. Examining patient and treatment characteristics associated with poorer performance on these PREMs and PROMs can highlight focal points for interventions such as patient sub-groups reporting more negative experiences of care $[32,36]$. However, only a handful of studies, largely from high-income countries, have used PREMS and PROMS for this purpose [32, 36, $39,40]$. Patient characteristics that may influence performance on these measures include age, gender, marital status, race/ethnicity, socio-economic status (employment and income), education, type of substance used, presence of co-occurring mental or physical health problems, treatment expectations, and prior experience of treatment $[36,39,40]$. Treatment characteristics associated with performance on these measures may include intensity of treatment (residential versus outpatient), type of treatment programme, and treatment duration [32].

Although, the pattern of patient and treatment factors associated with PREMs and PROMs is likely to 
vary between high-income and low-and middle-income countries (LMICs) due to differences in patient population and treatment system profiles, no studies have used patient-reported measures to identify targets for SUD treatment system strengthening in low-and middle-income countries. To address this gap and establish locally relevant targets for SUD treatment improvement initiatives, we explored factors associated with sub-optimal performance on PROMs and PREMs for a treatment population in South Africa, an upper-middle income country. More specifically, this paper aims to identify patient socio-demographic and substance use characteristics as well as treatment factors associated with suboptimal performance on patient-reported (1) access to, (2) quality and (3) SUD outcomes for the Western Cape province of South Africa's SUD treatment system.

\section{Methods}

\section{Study overview and setting}

For this paper, we examined patient-reported experience and outcome data collected during 2019 as part of the routine implementation of the Service Quality Measures (SQM) performance measurement system in the Western Cape Province of the country [41]. This system collects patient-level data from 32 treatment sites representing $90 \%$ of available treatment sites in the region [41].

The bulk of these treatment sites $(n=28)$ are dispersed across the eight health subdistricts of the Cape Town metropole, the most densely populated region of the province. The remainder of the treatment sites are in the rural Winelands region of the province. Treatment sites vary in size of treatment population, type of service offering (residential versus outpatient), and funding source $[11,12]$. The majority $(n=26)$ provide outpatient services, with only six providing residential care. Three of the 32 sites (all residential services) are private-forprofit facilities. The remainder of the services are either fully or partially funded through the state. None of these services focus on particular substances of concern (for example, opiates). As part of their funding requirements, all state-funded outpatient facilities offer either motivational enhancement therapy (MET), cognitive behavioral treatment (CBT) or the Matrix model of treatment as evidence-based treatments $[13,18]$. Residential programs tend to incorporate elements of MET, CBT and 12-step facilitation.

\section{SQM implementation and data collection procedures}

The SQM system was co-developed with service users and treatment providers in 2013 in response to an identified need [42, 43], before being initially implemented in six pilot sites in 2014 [44]. This co-design process identified strategies for overcoming potential implementation barriers and enhanced provider readiness to adopt the system [43-45]. Over time, system implementation protocols have evolved to enhance feasibility of implementation and its utility to providers [41]. System reach has expanded to 32 sites in the Western Cape as providers grew aware of the benefits of the system for treatment improvement $[41,43]$.

All SUD treatment sites voluntarily participating in SACENDU are invited to implement the SQM system. Project staff approached treatment managers at these facilities, described the SQM initiative and invited them to participate in system implementation. Facilities had to agree to (1) release staff for initial and ongoing training in the implementation protocols, (2) adopt the performance measurement data collection protocols, and (3) implement the SQM system for at least the minimal data collection period (spanning 1 August through 31 October each year). At the implementing sites, providers complete a standardised two-page SACENDU treatment admission form [22]. On admission, patients are informed about the system and are asked to consent to completing a patient survey about their treatment experiences. Less than 3\% of patients decline to participate in the system [41]. At least three weeks after entering treatment, patients are asked to complete the South African Addiction Treatment Services Assessment (SAATSA) [38] that includes several PREMS and PROMs. Patients who leave treatment prematurely often do not complete a SAATSA. This is a barrier for outpatient services, where treatment disengagement is high within the first two weeks of treatment [33]. Protocols require providers to re-contact patients and complete the SAATSA telephonically, but providers often experience difficulties in tracing patients who disengage from services [41]. Finally, providers complete a standardised discharge form on every patient within 30 days of treatment ending [30]. This form gathers information on type of treatment, duration, and clinicians' perceptions of the patient's treatment response [33]. Providers can complete this form with the patient or retrospectively, using data extracted from their case files and treatment records. A unique patient identifier allows for data extracted from these three forms to be combined to monitor access, effectiveness, quality, and efficiency of services.

Participating facilities are not financially incentivized to implement the system but are given individualized reports on their performance with data-led recommendations on how they can strengthen their programmes [41]. Providers are more likely to implement the SQM system with fidelity where their leaders and managers mandate implementation and are committed to using system findings for quality improvement [41]. 


\section{Measures}

The measures used in this paper include patient demographic and substance use variables extracted from the SACENDU admission form, PREMs and PROMs from the SAATSA, and treatment-related variables extracted from the discharge form.

\section{Sociodemographic characteristics}

We extracted data from the SACENDU form on patients' age, gender (male versus female), race (Black/ African, Coloured (persons of mixed race ancestry), White, or Indian descent), education (completed high school versus not completed high school), and employment status (yes/no).

\section{Clinical characteristics}

We extracted data from the SACENDU form on primary substance of use (stimulants like methamphetamine and cocaine, opiates, cannabis, methaqualone (Mandrax), and alcohol); presence of polysubstance use (yes/no); frequency of use (daily, 2-6 times per week, weekly, monthly); a continuous measure of number of years of substance use as an indicator of chronicity; and prior experience of SUD treatment (yes/no). We also extracted information from the SACENDU form on the presence of any known (1) physical noncommunicable diseases (NCDs) namely hypertension, cardiovascular disease, diabetes, respiratory disease, liver disease and gastrointestinal disease and separately (2) mental health diagnoses at the time of enrolment into SUD treatment. The SACENDU system does not record specific mental health diagnoses. While specific NCDs are recorded, many of the NCDs have small numbers of cases. We therefore created a dichotomous variable reflecting the presence or absence of any type of comorbid physical noncommunicable disease.

\section{Treatment factors}

Intensity of treatment provided (residential or outpatient), source of funding for treatment (state versus other) and completion of treatment (yes/no) were extracted from the SACENDU admission and SQM discharge form. Tratment completion was defined as completion of the specified treatment programme.

\section{PREMs and PROMs}

The SAATSA consists of four PROMs measuring changes in substance use, quality of life, social connectedness, and sexual risk behaviour and two PREMs assessing accessibility and overall quality of services [32]. For this paper, we report on system performance for the access, overall quality, and substance use measures.

The PREM relating to access comprises five items (such as "The amount of time I had to wait to get services was acceptable to me" and "It is easy for me to obtain the treatments offered by this centre") with patient responses ranging on a four-point scale from strongly disagree (0) to strongly agree (3). Composite scores, calculated by summing the responses, range between 0 and 15, with higher scores indicating fewer perceived difficulties in accessing services (Cronbach's alpha $=0.79$ ).

The PREM relating to quality comprises six SAATSA items related to theoretical understandings of personcentred care [32]. Examples of items include "I have a say in deciding about substance abuse treatment I am receiving here" and "The staff at this treatment centre are sensitive to my background." Items are scored using the patient response scale described earlier with composite scores ranging between 0 and 18 and higher total scores indicating more positive perceptions of the quality and personcentredness of treatment. A Cronbach's alpha coefficient of 0.83 was obtained for this measure.

The substance use PROM contains four SAATSA items that are scored using the identical patient response scale. Examples of items include "As a result of the treatment I have received I am less likely to use alcohol or other drugs" and "The treatment centre is helping me to recover from using alcohol and drugs." Composite scores range between 0 and 12, with higher scores indicating more positive outcomes. For this scale, the Cronbach's alpha coefficient was 0.81 .

\section{Analyses}

All analyses were conducted using Stata 16 (Stata Corporation, College Station, TX, USA), with significance set at $p<0.05$. We used Stata's survey analysis platform to account for clustering by treatment site. In 2019, the SQM system collected 3318 SACENDU admission, 1720 SAATSA, and 2569 SQM discharge forms. Of these, we were able to link a SACENDU admission, SAATSA, and SQM discharge form for 1139 cases. Of these, 42 cases had too much missing data from the SAATSA items to allow for the calculation of the PROM or PREMs. As the data seemed to be missing at random, and because these cases represented $\sim 3 \%$ of the sample with linked data, we decided to removing these cases using listwise deletion. The final dataset therefore included 1097 observations. We used adjusted Wald tests and t-tests to compare the demographic characteristics of the realized sample against that of the SACENDU treatment population for the specified reporting period. Next, as scores on each of the SAATSA scales were positively skewed, we recoded 
these into optimal versus sub-optimal performance after transforming the composite scale scores into percentage scores indicating the average percentage of the score relative to the total possible score. For the access and quality PREMs and substance use PROM, scores $<80 \%$ were coded as "substantial difficulties in accessing SUD treatment", "suboptimal quality of treatment", or "suboptimal SUD outcomes," respectively. Next, we conducted logistic regression (for categorial variables) and linear regression (for continuous variables) analyses to identify and describe possible relationships between socio-demographic, substance use, and treatment factors and sub-optimal performance on three patient-reported measures (access, quality, substance use outcomes). Variables associated with these measures at $p<0.10$ were entered in multivariable logistic regression models that adjusted for gender, age and race. Results are reported as adjusted odds ratios (aOR) with 95\% confidence intervals (CIs).

\section{Results}

\section{Sample characteristics}

The 1097 cases included in the analyses represent 33.1\% of the total SUD treatment population at participating sites. All 32 treatment sites are represented in the final sample. Table 1 compares the demographic characteristics of the included cases with the characteristics of cases not included in the analysis and the total treatment population. In the final sample, $26.3 \%$ of the cases were female, $7.7 \%$ were Black African and $80.4 \%$ were Coloured (a designated race in South Africa comprising people of mixed-race ancestry), the mean age was 33.4 years $(\mathrm{SD}=10.1), 51.4 \%$ had completed high school, and $73.7 \%$ were unemployed. Patients who were completed the SAATSA and were included in the analyses were more likely to have completed high school than those did not (51.4\% vs $46.3 \%, p=0.032$ ). In this sample and the treatment population, the two most frequently reported substances used were stimulants $(40.9 \%$ of the sample versus

Table 1 Baseline sociodemographic, substance use and treatment characteristics of cases included in the sample, compared to the overall treatment population

\begin{tabular}{|c|c|c|c|}
\hline Variable & $\begin{array}{l}\text { Included in the sample }(\mathrm{N}=1097) \\
\mathrm{n}(\%)\end{array}$ & $\begin{array}{l}\text { Not included in the sample } \\
(\mathrm{N}=2221) \\
\mathrm{n}(\%)\end{array}$ & $\begin{array}{l}\text { Overall treatment } \\
\text { population } \\
(\mathrm{N}=3318) \\
\mathrm{n}(\%)\end{array}$ \\
\hline \multicolumn{4}{|l|}{ Gender } \\
\hline Male & $808(73.7)$ & $1572(70.8)$ & $2380(71.7)$ \\
\hline Female & $289(26.3)$ & 649 (29.2) & $938(28.3)$ \\
\hline \multicolumn{4}{|l|}{ Race } \\
\hline Black African & $84(7.7)$ & $238(10.7)$ & $322(9.7)$ \\
\hline Coloured $^{\mathrm{a}}$ & $882(80.4)$ & $1755(79.0)$ & $2637(79.5)$ \\
\hline White & $103(9.1)$ & $218(9.8)$ & $321(9.7)$ \\
\hline Indian & $31(2.8)$ & $11(0.5)$ & $42(1.3)$ \\
\hline Age $(M, S D)$ in years & $33.4(10.1)$ & $32.7(9.8)$ & $33.1(9.9)$ \\
\hline \multicolumn{4}{|l|}{ Education } \\
\hline Completed school & $564(51.4)$ & $1028(46.3)^{*}$ & $1592(48.0)$ \\
\hline Not completed school & $533(48.6)$ & $1193(53.7)$ & $1726(52.0)$ \\
\hline \multicolumn{4}{|l|}{ Employment } \\
\hline Employed & $289(26.3)$ & $624(28.1)$ & $913(27.5)$ \\
\hline Unemployed & $808(73.7)$ & $1597(71.9)$ & $2405(72.5)$ \\
\hline \multicolumn{4}{|l|}{ Primary substance } \\
\hline Stimulants & $449(40.9)$ & $848(38.2)$ & $1297(39.1)$ \\
\hline Opiates & $325(29.6)$ & $515(23.2)$ & $840(25.3)$ \\
\hline Cannabis & $67(6.1)$ & $362(16.3)^{*}$ & $429(12.9)$ \\
\hline Methaqualone & $93(8.5)$ & $213(9.6)$ & $306(9.2)$ \\
\hline Alcohol & $163(14.9)$ & $282(12.7)$ & $445(13.4)$ \\
\hline \multicolumn{4}{|l|}{ Treatment intensity } \\
\hline Residential & $406(37.3)$ & $553(24.9)^{* *}$ & 959 (28.9) \\
\hline Outpatient & $688(62.7)$ & 1668 (75.1) & 2356 (71.0) \\
\hline
\end{tabular}

a "Coloured" refers to people of mixed race ancestry- a designated population group in South Africa

${ }^{*}$ significant at $p<0.05 * *$ significant at $p<0.01$ 
$39.1 \%$ of the treatment population), followed by opiates (29.6\% of the sample versus $25.3 \%$ of the treatment population). Patients reporting cannabis as their primary substance were slightly under-represented in the analytic sample compared to the overall treatment population (6.1\% vs. $12.9 \%)$. In terms of treatment intensity, patients who completed the SAATSA and were included in the analyses were more likely to have obtained residential treatment than those excluded from the analyses (37.3\% vs $24.9 \%, p=0.002$; Table 1 ).

\section{Patient-reported access to, quality of, and outcomes of treatment}

Of the patients who completed the SAATSA measure, $37.9 \%$ (95\% CI 29.7\%; 46.8\%) erceived substantial difficulties in accessing SUD treatment, $28.8 \%$ (95\% CI: 23.7\%; $34.4 \%)$ perceived SUD treatment to be of suboptimal quality, and $31.1 \%$ (95\% CI 24.4\%; 38.8\%) reported suboptimal SUD outcomes.

\section{Variables associated with greater perceived difficulty in accessing SUD treatment}

Factors associated with perceived access to SUD treatment in unadjusted analyses included race, presence of co-occurring physical noncommunicable diseases or mental health problems, type of substance used, polysubstance use, chronicity of substance use, the source of payment for treatment and the intensity of treatment (Table 2). In multivariate analyses, several of these factors remained independently associated with perceived access to treatment. Patients who self-identified as Coloured or White were significantly less likely to perceive difficulties in accessing SUD treatment than participants who self-identified as Black African $(\mathrm{aOR}=0.23$; $95 \%$ CI $0.11-0.51 ; \mathrm{aOR}=0.28 ; 95 \%$ CI $0.11-0.71$, respectively). Patients with comorbid mental health problems had significantly greater odds of experiencing suboptimal access to treatment than patients without these difficulties $(\mathrm{aOR}=1.91 ; 95 \%$ CI 1.16-3.14). The odds of experiencing suboptimal access to SUD treatment was elevated for patients in residential treatment $(\mathrm{aOR}=1.69$; 95\% CI 1.08-2,64) and with chronicity of substance use $(\mathrm{aOR}=1.02$; 95\% CI 1.02-1.05; Table 2).

\section{Variables associated with patient perceptions of suboptimal SUD treatment quality}

In unadjusted analyses, race, polysubstance use, chronicity of substance use, and prior experience of SUD treatment were associated with perceptions of suboptimal quality of SUD treatment (Table 3). In multivariate analyses, race remained independently associated with suboptimal SUD treatment quality. Patients who self-identified as Coloured were significantly less likely to perceive SUD treatment as being of poorer quality than those who were Black African $(\mathrm{aOR}=0.32 ; 95 \% \mathrm{CI}$ 0.16-0.66). The odds of perceiving SUD treatment to be of suboptimal quality increased as years of substance use increased ( $\mathrm{aOR}=1.03 ; 95 \% \mathrm{CI} 1.00-1.05)$. Patients with comorbid mental health problems $(\mathrm{aOR}=2.08 ; 95 \% \mathrm{CI}$ 1.24-3.49), and who had previous experience of SUD treatment $(\mathrm{aOR}=1.79 ; 95 \% \mathrm{CI} 1.42-2.51)$ were more likely to report experiencing treatment of suboptimal quality (Table 3).

To better understand the association between race and perceptions of SUD treatment quality, we explored associations between race and the individual items comprising this PREM. Notably, a higher proportion of Black African patients reported provider insensitivity to cultural background (16.8\%) compared to Coloured (5.9\%), White $(6.2 \%)$ and Indian (5.6\%) patients $(p=0.002)$. Similarly, when we explored the SAATSA item assessing patient perceptions of being treated with respect, significantly more Black African patients reported not being treated with respect $(10.8 \%)$ compared to Coloured (4.8\%), White (5.1\%) and Indian (3.2\%) patients $(p=0.041)$. Black African patients were also more likely to report a lack of involvement in their SUD treatment planning (12.6\%) compared to Coloured (4.7\%), White $(4.2 \%)$ and Indian (3.6\%) patients $(p=0.035)$.

\section{Factors associated with patient perceptions of suboptimal SUD outcomes}

In unadjusted analyses, age, polysubstance use, comorbid mental health problems, failure to complete treatment, and perceptions of suboptimal treatment quality were the only variables significantly associated with patient perceptions of suboptimal SUD outcomes (Table 4). In multivariate analyses, women were significantly less likely to report suboptimal SUD outcomes than men $(\mathrm{aOR}=0.57$; 95\% CI 0.35-0.93). The odds of experiencing suboptimal treatment outcomes were greater amongst patients with comorbid mental health problems $(\mathrm{aOR}=1.41 ; 95 \% \mathrm{CI}$ 1.02-2.05) and for patients reporting polysubstance use $(\mathrm{aOR}=1.68 ; 95 \%$ CI 1.11-2.55). Patients who did not complete their full treatment programme had triple the odds of reporting poorer outcomes than those who completed their programme as planned $(\mathrm{aOR}=3.03 ; 95 \% \mathrm{CI}$ 1.33-6.86). Patients who perceived SUD treatment to be of suboptimal quality had substantially elevated odds of reporting suboptimal treatment outcomes $(\mathrm{aOR}=20.82$; 95\% CI 13.59-31.88; Table 4).

\section{Discussion}

To the best of our knowledge, no other studies from LMICs have used data from patient-reported measures to identify targets for SUD treatment system 
Table 2 Sociodemographic, substance use and treatment variables associated with greater perceived difficulty in accessing SUD treatment $(n=1097)$

\begin{tabular}{|c|c|c|c|c|c|}
\hline \multirow[t]{2}{*}{ Variable } & \multirow{2}{*}{$\begin{array}{l}\text { Poor performance on } \\
\text { SAATSA Access Scale } \\
n(\%)\end{array}$} & \multicolumn{2}{|c|}{ Unadjusted association } & \multicolumn{2}{|c|}{ Adjusted association } \\
\hline & & $\mathrm{OR}^{\mathrm{a}}$ & $95 \% \mathrm{Cl}^{\mathrm{b}}$ & $\mathrm{aOR}^{\mathrm{c}}$ & $95 \% \mathrm{Cl}$ \\
\hline \multicolumn{6}{|l|}{ Gender } \\
\hline Male & $318(39.1)$ & Reference & & Reference & \\
\hline Female & $99(35.0)$ & 0.84 & $0.59-1.19$ & 0.89 & $0.69-1.27$ \\
\hline \multicolumn{6}{|l|}{ Race } \\
\hline Black African & $44(57.1)$ & Reference & & Reference & \\
\hline Coloured $^{d}$ & $308(34.9)$ & 0.22 & $0.12-0.40^{* * *}$ & 0.23 & $0.11-0.51^{* * *}$ \\
\hline White & $60(41.6)$ & 0.34 & $0.21-0.57^{* * *}$ & 0.28 & $0.11-0.71^{* *}$ \\
\hline Indian & $5(47.6)$ & 1.24 & $0.10-14.96$ & 1.24 & $0.11-12.70$ \\
\hline Age $(M, S E)$ in years & $33.7(0.58)$ & 1.01 & $0.99-1.03$ & 0.98 & $0.96-1.00$ \\
\hline \multicolumn{6}{|l|}{ Education } \\
\hline Not completed school & $174(33.0)$ & 0.66 & $0.41-1.07$ & - & \\
\hline \multicolumn{6}{|l|}{ Employment } \\
\hline Employed & $127(44.2)$ & 1.42 & $0.99-2.05$ & 1.13 & $0.71-1.75$ \\
\hline $\begin{array}{l}\text { Comorbid physical noncommunica- } \\
\text { ble disease }\end{array}$ & $56(50.0)$ & 1.84 & $1.26-2.70^{* * *}$ & 1.84 & $0.99-3.52$ \\
\hline Comorbid mental health & $51(51.0)$ & 1.92 & $1.01-3.88^{*}$ & 1.91 & $1.16-3.14^{* *}$ \\
\hline \multicolumn{6}{|l|}{ Primary substance } \\
\hline Stimulants & $145(35.1)$ & 0.58 & $0.40-0.84^{* *}$ & 0.84 & $0.46-1.58$ \\
\hline Heroin & $96(36.5)$ & 0.51 & $0.35-0.74^{* *}$ & 1.03 & $0.45-2.36$ \\
\hline Cannabis & $23(32.1)$ & 0.61 & $0.38-0.98^{*}$ & 0.81 & $0.40-1.62$ \\
\hline Methaqualone & $34(40.0)$ & 0.71 & $0.35-1.44$ & 1.04 & $0.43-2.23$ \\
\hline Alcohol & $73(48.3)$ & Reference & & Reference & \\
\hline Polysubstance use & $227(35.0)$ & 1.32 & $1.01-1.75^{*}$ & 1.26 & $0.89-1.79$ \\
\hline Chronicity: years of use $(M, S E)$ & $15.12(0.79)$ & 1.02 & $1.00-1.03^{*}$ & 1.02 & $1.02-1.05^{* *}$ \\
\hline \multicolumn{6}{|l|}{ Frequency of use } \\
\hline Daily & $276(35.7)$ & 2.41 & $0.52-1.10$ & - & \\
\hline 2-6 times per week & $84(42.2)$ & 3.17 & $0.69-14.57$ & & \\
\hline Weekly & $10(37.0)$ & 2.54 & $0.53-12.28$ & & \\
\hline Monthly & $3(18.8)$ & Reference & & & \\
\hline Prior SUD treatment No & $190(37.7)$ & Reference & & & \\
\hline Yes & $227(38.2)$ & 1.02 & $0.79-1.32$ & - & \\
\hline \multicolumn{6}{|l|}{ Treatment intensity } \\
\hline Outpatient & $215(31.6)$ & Reference & & Reference & \\
\hline Residential & $202(48.4)$ & 2.03 & $1.40-2.96^{* *}$ & 1.69 & $1.08-2.64^{* *}$ \\
\hline \multicolumn{6}{|l|}{ State-funded treatment } \\
\hline Yes & $286(34.3)$ & 0.53 & $0.29-0.96^{*}$ & 0.90 & $0.53-1.54$ \\
\hline No & $131(49.8)$ & Reference & & Reference & \\
\hline
\end{tabular}

${ }^{\mathrm{a}}$ OR odds ratio, ${ }^{\mathrm{b}} 95 \% \mathrm{Cl} 95 \%$ confidence interval; ${ }^{\mathrm{c}} \mathrm{AOR}$ adjusted odds ratio; ${ }^{\mathrm{d} u}$ Coloured" refers to people of mixed race ancestry- a designated population group in South Africa

* significant at $p<0.05,{ }^{* *}$ significant at $p<0.01,{ }^{* * *}$ significant at $p<0.001$

strengthening. To address this gap, we describe the performance of the Western Cape's SUD treatment system on patient-reported measures of treatment access, quality, and outcomes. With more than a third of participants reporting substantial difficulties in accessing SUD treatment and more than a quarter describing suboptimal quality of care, our findings confirm that access to quality SUD treatment remains challenging for a substantial proportion of people with SUDs despite system-level efforts to scale up the availability of evidence-based SUD treatment in this province [18-20]. Findings that almost a third of patients report unsatisfactory SUD outcomes, 
Table 3 Sociodemographic, substance use and treatment variables associated with patient perceptions that SUD treatment was of suboptimal quality $(n=1097)$

\begin{tabular}{|c|c|c|c|c|c|}
\hline \multirow[t]{2}{*}{ Variable } & \multirow{2}{*}{$\begin{array}{l}\text { Poor performance on } \\
\text { SAATSA Quality Scale } \\
n(\%)\end{array}$} & \multicolumn{2}{|c|}{ Unadjusted association } & \multicolumn{2}{|c|}{ Adjusted association } \\
\hline & & $\mathrm{OR}^{\mathrm{a}}$ & $95 \% \mathrm{Cl}^{\mathrm{b}}$ & $\mathrm{aOR}^{\mathrm{c}}$ & $95 \% \mathrm{Cl}$ \\
\hline \multicolumn{6}{|l|}{ Gender } \\
\hline Male & $241(29.6)$ & Reference & & Reference & \\
\hline Female & $77(27.1)$ & 0.89 & $0.65-1.21$ & 0.76 & $0.51-1.14$ \\
\hline \multicolumn{6}{|l|}{ Race } \\
\hline Black African & 35 (44.9) & Reference & & Reference & \\
\hline Coloured $^{d}$ & $226(25.5)$ & 0.42 & $0.30-0.60^{* * *}$ & 0.32 & $0.16-0.66^{* *}$ \\
\hline White & $57(41.5)$ & 0.87 & $0.59-1.28$ & 0.57 & $0.30-1.07$ \\
\hline Indian & $6(50.0)$ & 1.23 & $0.34-4.43$ & 3.62 & $0.39-32.25$ \\
\hline Age $(M, S E)$ in years & $34.11(0.59)$ & 1.01 & $0.99-1.03$ & 0.97 & $0.96-1.02$ \\
\hline \multicolumn{6}{|l|}{ Education } \\
\hline Not completed school & $135(25.3)$ & 0.71 & $0.46-1.09$ & - & \\
\hline \multicolumn{6}{|l|}{ Employment } \\
\hline Employed & $100(35.0)$ & 0.68 & $0.43-1.09$ & - & \\
\hline $\begin{array}{l}\text { Comorbid physical noncommunicable } \\
\text { disease }\end{array}$ & $36(33.0)$ & 1.63 & $0.92-1.83$ & 1.14 & $0.78-1.76$ \\
\hline Comorbid mental health & $46(45.1)$ & 2.31 & $0.97-5.52$ & 2.08 & $1.24-3.49^{* *}$ \\
\hline \multicolumn{6}{|l|}{ Primary substance } \\
\hline Stimulants & $112(26.9)$ & 0.63 & $0.38-1.64$ & - & \\
\hline Heroin & $80(26.4)$ & 0.61 & $0.34-1.09$ & & \\
\hline Cannabis & $19(30.7)$ & 0.76 & $0.43-1.32$ & & \\
\hline Methaqualone & $20(23.5)$ & 0.53 & $0.16-1.73$ & & \\
\hline Alcohol & 55 (36.9) & Reference & & & \\
\hline Polysubstance use & $173(26.7)$ & 1.33 & $1.01-1.77^{*}$ & 1.25 & $0.88-1.77$ \\
\hline Chronicity: years of use $(M, S E)$ & $15.39(0.72)$ & 1.02 & $1.01-1.04^{* *}$ & 1.03 & $1.00-1.05^{*}$ \\
\hline \multicolumn{6}{|l|}{ Frequency of use } \\
\hline Daily & $199(25.8)$ & 1.22 & $0.32-4.08$ & - & \\
\hline 2-6 times per week & $77(38.1)$ & 2.16 & $0.52-9.02$ & & \\
\hline Weekly & $6(23.1)$ & 1.05 & $0.17-6.35$ & & \\
\hline Monthly & $4(22.2)$ & Reference & & & \\
\hline \multicolumn{6}{|l|}{ Prior SUD treatment } \\
\hline No & $154(26.0)$ & Reference & & Reference & \\
\hline Yes & $164(32.4)$ & 1.36 & $1.13-1.64^{* *}$ & 1.79 & $1.28-2.51^{* * *}$ \\
\hline Treatment intensity Outpatient & $176(25.8)$ & Reference & & - & \\
\hline Residential & $142(34.1)$ & 1.49 & $0.77-2.90$ & & \\
\hline \multicolumn{6}{|l|}{ State-funded treatment } \\
\hline Yes & $217(26.0)$ & 0.57 & $0.25-1.33$ & - & \\
\hline No & $101(38.1)$ & Reference & & & \\
\hline
\end{tabular}

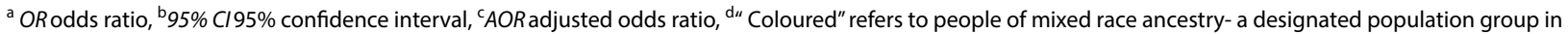
South Africa

${ }^{*}$ significant at $\mathrm{p}<0.05,{ }^{* *}$ significant at $\mathrm{p}<0.01,{ }^{* * *}$ significant at $\mathrm{p}<0.001$

with patient perceptions of suboptimal treatment quality being the variable most strongly associated with these poor outcomes, suggest that the Western Cape is unlikely to see a return on its investment in SUD treatment without systems-level interventions to improve the quality of existing SUD treatment services.
Our findings not only underscore the considerable need for SUD treatment quality improvement in this region, but also highlight disparities in treatment experiences and outcomes that require urgent intervention to ensure equitable access to quality treatment. Notably, patients who self-identified as Black African were more 
Table 4 Sociodemographic, substance use and treatment variables associated with patient perceptions of suboptimal SUD treatment outcomes $(n=1097)$

\begin{tabular}{|c|c|c|c|c|c|}
\hline \multirow[t]{2}{*}{ Variable } & \multirow{2}{*}{$\begin{array}{l}\text { Poor performance on } \\
\text { substance use PROM } \\
n(\%)\end{array}$} & \multicolumn{2}{|c|}{ Unadjusted association } & \multicolumn{2}{|c|}{ Adjusted association } \\
\hline & & $O R^{a}$ & $95 \% \mathrm{Cl}^{\mathrm{b}}$ & $\mathrm{aOR}^{\mathrm{c}}$ & $95 \% \mathrm{Cl}$ \\
\hline \multicolumn{6}{|l|}{ Gender } \\
\hline Male & $265(32.3)$ & Reference & & Reference & \\
\hline Female & $82(28.8)$ & 0.84 & $0.61-1.19$ & 0.57 & $0.35-0.93^{*}$ \\
\hline \multicolumn{6}{|l|}{ Race } \\
\hline Black African & $30(37.9)$ & Reference & & Reference & \\
\hline Coloured $^{d}$ & $265(29.8)$ & 0.69 & $0.42-1.15$ & 1.24 & $0.38-4.08$ \\
\hline White & $51(40.2)$ & 1.10 & $0.75-1.61$ & 2.07 & $0.76-5.63$ \\
\hline Indian & $1(8.3)$ & 0.15 & $0.02-1.19$ & 0.11 & $0.00-5.53$ \\
\hline Age $(M, S E)$ in years & $33.31(0.59)$ & 1.01 & $1.00-1.02^{*}$ & 1.01 & $0.99-1.04$ \\
\hline \multicolumn{6}{|l|}{ Education } \\
\hline Not completed school & $157(29.3)$ & 0.83 & $0.62-1.11$ & - & \\
\hline \multicolumn{6}{|l|}{ Employment } \\
\hline Employed & $93(32.3)$ & 1.06 & $0.57-1.95$ & - & \\
\hline Comorbid physical noncommunicable disease & $40(38.5)$ & 1.51 & $0.66-3.42$ & - & \\
\hline Comorbid mental health & $40(35.7)$ & 1.32 & $1.06-1.66^{* *}$ & 1.41 & $1.02-2.05^{*}$ \\
\hline \multicolumn{6}{|l|}{ Primary substance } \\
\hline Stimulants & $121(28.8)$ & 0.94 & $0.46-1.92$ & - & \\
\hline Heroin & $99(32.5)$ & 1.12 & $0.52-2.39$ & & \\
\hline Cannabis & $23(37.1)$ & 1.37 & $0.82-2.28$ & & \\
\hline Methaqualone & $21(24.7)$ & 0.76 & $0.17-3.52$ & & \\
\hline Alcohol & $46(30.1)$ & Reference & & Reference & \\
\hline Polysubstance use & $185(28.4)$ & 1.56 & $1.19-2.05^{* * *}$ & 1.68 & $1.11-2.55^{*}$ \\
\hline Chronicity: years of use $(M, S E)$ & $14.66(0.59)$ & 1.01 & $0.99-1.02$ & 0.98 & $0.96-1.01$ \\
\hline \multicolumn{6}{|l|}{ Frequency of use } \\
\hline Daily & $199(25.8)$ & 0.89 & $0.31-2.50$ & - & \\
\hline 2-6 times per week & $77(38.1)$ & 1.22 & $0.34-4.46$ & & \\
\hline Weekly & $6(23.1)$ & 0.54 & $0.09-3.22$ & & \\
\hline Monthly & $4(22.2)$ & Reference & & & \\
\hline \multicolumn{6}{|l|}{ Prior SUD treatment } \\
\hline No & $154(26.0)$ & Reference & & Reference & \\
\hline Yes & $164(32.4)$ & 1.18 & $0.91-1.54$ & 1.08 & $0.73-1.61$ \\
\hline Treatment intensity Outpatient & $229(33.3)$ & Reference & & - & \\
\hline Residential & $118(28.2)$ & 0.78 & $0.38-1.61$ & & \\
\hline \multicolumn{6}{|l|}{ State-funded treatment } \\
\hline Yes & $262(31.3)$ & 0.98 & $0.43-2.21$ & - & \\
\hline No & $85(31.7)$ & Reference & & & \\
\hline Did not complete treatment & $21(46.7)$ & 1.97 & $1.06-3.68^{*}$ & 3.03 & $1.33-6.86^{* *}$ \\
\hline Treatment quality perceived as suboptimal & $230(73.0)$ & 16.31 & $0.97-24.25^{* * *}$ & 20.82 & $13.59-31.88^{* * *}$ \\
\hline
\end{tabular}

${ }^{\mathrm{a}}$ OR odds ratio, ${ }^{\mathrm{b}} 95 \% \mathrm{Cl} 95 \%$ confidence interval, ${ }^{\mathrm{C}} \mathrm{AOR}$ adjusted odds ratio, ${ }^{\mathrm{d} u}$ Coloured" refers to people of mixed race ancestry- a designated population group in South Africa

${ }^{*}$ significant at $p<0.05,{ }^{*}$ significant at $p<0.01,{ }^{* * *}$ significant at $p<0.001$

likely to report inadequate access to and suboptimal quality of SUD treatment than patients from other racial groups, reflecting persisting racial disparities in the country's SUD services. Interventions that improve access to and the experience of SUD treatment for people who identify as Black/African require prioritisation to ensure health equity and redress apartheid's legacy of substandard health and social services for Black/African citizens. With less than one percent of SUD facilities located in predominantly Black/African communities and evidence 
that the cost and time burden associated with obtaining SUD treatment is higher for patients from Black/African communities than from communities well-served by treatment facilities [46], it is not surprising that patients of Black/African descent report more difficulties in obtaining treatment than other groups. Redressing these inequities will require treatment planners to locate new SUD services in underserved Black/African communities and consider the geospatial redistribution of existing SUD services in relation to unmet treatment need.

Our findings further suggest insufficient provision of culturally tailored, patient-centred SUD services. Specifically, patients of Black/African descent were more likely to report provider insensitivity to their (cultural) background not being treated with respect and lack of involvement in treatment planning. These findings are not surprising given that only three of the 32 sites were able to provide SUD services in isiXhosa, the most frequently spoken African language in the Western Cape. Associations between absence of culturally tailored, person-centred SUD treatment and suboptimal SUD outcomes among African migrant populations and racial minorities in high-income country studies $[47,48]$ underscore the need for systems-level interventions to improve Black/African patients' experience of care. Interventions that increase the cultural and language diversity of SUD providers in the Western Cape, expand SUD workforce training efforts to include cultural explanations of SUDs, and implement training to not only improve providers' cultural competence but also address their unconscious biases towards people of Black/African descent may help improve the SUD treatment experience of Black/ African patients. The latter may be especially relevant as institutional racism continues to cloud the interactions of patients and providers from different race groups in South Africa [49].

Disparities in access to and outcomes of SUD treatment for patients with comorbid mental disorders also emerged as a target for quality improvement. Findings indicate substantially greater risk of suboptimal access to, quality, and outcomes of SUD treatment among patients with comorbid mental and substance use disorders (MSUD) than patients with SUD alone. This study provides the first empirical evidence to support long-standing concerns about the relevance and appropriateness of South Africa's SUD services for people with comorbid MSUD [50, 51]. South Africa's publicly funded SUD treatment system rarely provides integrated SUD and mental health treatment, largely due to a lack of intersectoral collaboration between the separate SUD and mental health treatment systems that has resulted in SUD providers often lacking the training and skills to address comorbid mental disorders among people with SUDs
[51, 52]. While SUD providers do refer patients with comorbid conditions to external mental health services, patients struggle to access chronically under-resourced public sector services due to long waiting periods, provider stigma towards people with SUDs, and other patient barriers $[51,53]$.

With at least $50 \%$ of patients estimated to have comorbid MSUD [54, 55], publicly funded SUD services must introduce integrated MSUD services to optimise the overall impact of SUD treatment. Evidence-based integrated MSUD treatments exist, with some already developed for the South African context [56, 57]. As social work professionals and lay addiction counsellors with limited training in mental disorders comprise the bulk of South Africa's SUD providers [51], implementing these programmes will require additional workforce development. With specialist mental health providers being a scarce resource in the country [53], expanding SUD treatment teams to include specialist providers is not realistic. Instead, we recommend drawing on the experiences of the global mental health movement which has demonstrated that structured evidence-based treatments for common mental disorders (like depression, anxiety and psychological trauma) can be task-shifted to nonspecialist providers with adequate training and support [58]. Local studies have shown that these task-shifted interventions are feasible to implement and acceptable to providers and patients with comorbid MSUD [59, 60]. Should SUD treatment planners implement this recommendation, current SUD workforce development initiatives [20] could be expanded to include capacitation of SUD providers on the necessary core competencies.

Our findings further suggest that risk of experiencing suboptimal access to and quality of SUD treatment is greater amongst patients with lengthier histories of substance-related problems than those with less complex clinical presentations. This may be due to the configuration of the Western Cape's SUD treatment system. Here, SUD treatment is provided mainly through outpatient services, with a limited number of residential facilities available. In this study, patients reported greater difficulty in accessing residential than outpatient services. The restricted supply of residential SUD treatment, the level of care most appropriate for individuals with chronic and severe SUDs [33], may explain why individuals with chronic problems experience greater difficulties in accessing care. Further, most SUD programmes in this region are of limited duration (21-28 days). The responsiveness of such programmes to the multiple needs of individuals with chronic SUDs is questionable. Although the intention is for patients to access continued support post-treatment, through structured aftercare or mutual/ self-help support programmes, little is known about 
existing continued care services. A better understanding of the structure and content of these continued support programmes (as well as patient perceptions of their utility) is needed to guide efforts to improve the appropriateness of SUD services for people with chronic SUDs.

There are some limitations to consider when interpreting these findings. With SQM system implementation being restricted to the Western Cape, findings may not be generalizable to other provinces. The type of SUD treatment provided is similar across the country, but there are interprovincial differences in the prevalence of SUD and the sociodemographic and substance use characteristics of people who use substances [11] that are likely to influence experiences and responses to treatment. Furthermore, our analyses are limited to a third of the total number of treatment episodes at participating sites. Although baseline characteristics of the included cases and overall treatment population seemed similar, residential treatment episodes were overrepresented in our sample (likely due to high rates of attrition from outpatient treatment), which may have influenced findings. In addition, as analyses were limited to variables included in the SQM system, we were unable to assess other patient (e.g. motivation or treatment expectations) or other treatment-related factors (such as type of treatment programme or counsellor characteristics) known to be associated with patient perceptions and outcomes of SUD interventions in this setting [61]. In response to these system limitations, we are now collecting detailed information from each participating SUD treatment facility on the type of treatment provided and composition of SUD providers that will enable a more nuanced and comprehensive analysis of the correlates of patientreported experiences and outcomes of SUD treatment in this setting.

\section{Conclusion}

This study is among the first to use routinely collected patient-reported measures to identify targets for SUD treatment system improvement in a LMIC. With a substantial proportion of participants reporting difficulties in accessing SUD treatment, suboptimal quality of care, and unsatisfactory SUD outcomes, there is a clear need for SUD treatment quality improvement initiatives in this setting. Our findings also highlight the need for targeted efforts to ensure equitable access to quality treatment for patients of Black/African descent and those with more complex and severe clinical presentations. We propose a variety of systems-level interventions to improve the quality of care, and ultimately the SUD treatment outcomes, for these patient subgroups that include reconsidering the spatial distribution of SUD services to improve access to SUD treatment in
Black/African communities, workforce development interventions to build cultural competency and address unconscious racial bias among providers, building provider competency to deliver evidence-based integrated MSUD services (and supporting them in programme implementation), and re-looking at the role of continued care and support services for patients with more complex and chronic SUDs. Although these findings are specific to the South African treatment context, our findings demonstrate the benefits of collecting PREMs and PROMs through a routinely implemented performance measurement system and how these data can be used to guide SUD treatment improvement initiatives in resource-limited contexts. The PREMs and PROMs contained in the SQM system could easily be adapted for implementation in other low-and middle-income countries and are likely to be highly acceptable to patients and treatment facilities, provided that the process of adapting the measures for cultural fit follows a co-design process.

\section{Abbreviations \\ LMIC: Low-and middle-income country; PREM: Patient-reported experience measure; PROM: Patient-reported outcome measure; SAATSA: South African Addiction Treatment Services Assessment; SACENDU: South African Commu- nity Epidemiology Network on Drug Use; SQM: Service quality measures; SUD: Substance use disorder.}

\section{Acknowledgements}

We wish to thank all service users and SUD treatment centres that participate in the SQM initiative and routinely provide data on their services.

\section{Authors' contributions}

$\mathrm{BM}$, JRK conceived the study design. KJ oversaw data collection and management. BM conducted statistical analyses. Bronwyn Myers wrote the first draft of the manuscript which JRK, NH and KJ critically reviewed and revised. All authors have read and approved the final manuscript.

\section{Funding}

The South African Medical Research Council (SAMRC) funded this study, with partial funding for the SACENDU project obtained from the South African National Department of Health (SA-NDoH). The SAMRC and NDoH had no role in the collection, analysis and interpretation of data; in the writing of the paper; or in the decision to submit the paper for publication.

\section{Availability of data and materials}

Data and materials are available on request from the corresponding author.

\section{Declarations}

\section{Ethics approval and consent to participate}

The South African Medical Research Council's Ethics Committee approved this study (EC 001-2/2014). All facilities consented to participate in the system, and patients consented to their de-identified demographic and treatment information being shared with researchers as part of the SQM initiative.

\section{Consent for publication}

Not applicable.

Competing interests

The authors report no declarations of interest. 


\section{Author details}

${ }^{1}$ Curtin enAble Institute, Faculty of Health Sciences, Curtin University, Kent Street, Bentley, WA 6102, Australia. ${ }^{2}$ Alcohol, Tobacco and Other Drug Research Unit, South African Medical Research Council, Cape Town, South Africa. ${ }^{3}$ Division of Addiction Psychiatry, Department of Psychiatry and Mental Health, University of Cape Town, Cape Town, South Africa. ${ }^{4}$ Department of Psychology, Virginia Commonwealth University, Richmond, VA, USA. ${ }^{5}$ School of Public Health, University of Cape Town, Cape Town, South Africa.

Received: 3 August 2021 Accepted: 18 January 2022

Published online: 02 February 2022

\section{References}

1. Global burden of disease 2016 Alcohol and Drug Use Collaborators. The global burden of disease attributable to alcohol and drug use in 195 countries and territories, 1990-2016: a systematic analysis for the Global Burden of Disease Study 2016. Lancet Psychiatry. 2017;5(12):987-1012. https://doi.org/10.1016/S2215-0366(18)30337-7.

2. Global burden of disease 2017 Disease and Injury Incidence and Prevalence Collaborators. Global, regional, and national incidence, prevalence, and years lived with disability for 354 diseases and injuries for 195 countries and territories, 1990-2017: a systematic analysis for the Global Burden of Disease Study 2017. Lancet. 2018;392(10159):1789-858. https://doi.org/10.1016/S0140-6736(18)32279-7.

3. United Nations. Transforming our world: the 2030 agenda for sustainable development. Resolution of the United Nations General Assembly. Vienna: United Nations; 2015. https://sustainabledevelopment.un.org/ content/documents/21252030\%20Agenda\%20for\%20Sustainable\% 20Development\%20web.pdf. Accessed 19 Nov 2020.

4. Pengpid S, Peltzer K, Ramlagan S. Prevalence and correlates of hazardous, harmful or dependent alcohol use and drug use amongst persons 15 years and older in South Africa: results of a national survey in 2017. Afr J Prim Health Care Fam Med. 2021;13(1):e1-8. https://doi.org/10.4102/ phcfm.v13i1.2847.

5. Pasche S, Myers B. Substance misuse trends in South Africa. Hum Psychopharmacol Clin Exp. 2012;27:338-41. https://doi.org/10.1002/hup. 2228

6. Herman AA, Williams DR, Stein DJ, Seedat S, Heeringa S, Moomal H. The South African Stress and Health Study (SASH). S Afr Med J. 2009;99(5):339.

7. Harker Burnhams N, Bharat C, Williams DR, Stein DJ, Myers B. Transitions between lifetime alcohol use, regular use and remission: results from the 2004 South African Stress and Health Survey. S Afr Med J. 2018;109(1):40-6.

8. Degenhardt L, Charlson F, Ferrari A, et al. The global burden of disease attributable to alcohol and drug use in 195 countries and territories, 1990-2016: a systematic analysis for the Global Burden of Disease Study 2016. Lancet Psychiatry. 2018;5(12):987-1012.

9. Meade CS, Towe SL, Watt MH, Lion RR, Myers B. Addiction and treatment experiences among active methamphetamine users recruited from a township community in Cape Town, South Africa: a mixed-methods study. Drug Alcohol Depend. 2015;152:79-86. https://doi.org/10.1016/j. drugalcdep.2015.04.016.

10. Myers B, Kline LT, Doherty Al, Carney T, Wechsberg WM. Perceived need for substance use treatment among young women from disadvantaged communities in Cape Town, South Africa. BMC Psychiatry. 2014;14:100. https://doi.org/10.1186/1471-244X-14-100.

11. Harker N, Lucas WC, Laubscher R, Dada S, Myers B, Parry CDH. Is South Africa being spared the global opioid crisis? A review of trends in drug treatment demand for heroin, nyaope and codeine-related medicines in South Africa (2012-2017). Int J Drug Policy. 2020;83: 102839. https://doi. org/10.1016/j.drugpo.2020.102839.

12. Dada S, Burnhams N, Laubscher R, Myers B, Parry CDH. Changes in alcohol and other drug use among women admitted to specialist substance abuse treatment centres in the Western Cape (2000-2013). South Afr J Sci. 2018;114:48-54. https://doi.org/10.17159/sajs.2018/4451.

13. Temmingh $H$, Myers $B$. Clinical treatment of substance use disorders in South Africa. In: Ellis G, Stein DJ, Meintjies E, Thomas K, editors. Substance use and abuse in south africa brain behavioural and other perspectives. Cape Town: University of Cape Town Press; 2012. p. 329-66.

14. Scheibe A, Marks M, Shelly S, Gerardy T, Domingo A, Hugo J. Developing an advocacy agenda for increasing access to opioid substitution therapy as part of comprehensive services for people who use drugs in South Africa. S Afr Med J. 2018;108(10):800-2.

15. Magidson JF, Lee JS, Johnson K, Burnhams W, Koch JR, Manderscheid R, et al. Openness to adopting evidence-based practice in public substance abuse treatment in South Africa using task shifting: caseload size matters. Subst Abuse. 2018;39:162-6. https://doi.org/10.1080/08897077.2017. 1380743.

16. Myers B, Louw J, Pasche S. Inequitable access to substance abuse treatment services in Cape Town, South Africa. Subst Abuse Treat Prev Policy. 2010;5:28. https://doi.org/10.1186/1747-597X-5-28.

17. Pasche S, Kleintjes S, Wilson D, Stein DJ, Myers B. Improving addiction care in South Africa: development and challenges to implementing training in addictions care at the University of Cape Town. Int J Ment Health Addict. 2015;13:322-32. https://doi.org/10.1007/s11469-014-9537-7.

18. Gouse H, Magidson JF, Burnhams W, Remmert JE, Myers B, Joska J, et al. Implementation of cognitive-behavioral substance abuse treatment in Sub-Saharan Africa: treatment engagement and abstinence at treatment exit. PLOS ONE. 2016;11: e0147900. https://doi.org/10.1371/journal.pone. 0147900

19. Magidson JF, Gouse H, Burnhams W, Wu CY, Myers B, Joska JA, et al. Beyond methamphetamine: documenting the implementation of the matrix model of substance use treatment for opioid users in a South African setting. Addict Behav. 2017;66:132-7. https://doi.org/10.1016/j. addbeh.2016.11.014.

20. Scott K, Sibeko G, Cummings B, Myers B, Sorsdahl K, Stein DJ, et al. Training the addiction treatment workforce in HIV endemic regions: an overview of the South Africa HIV addiction technology transfer center initiative. Train Educ Prof Psychol. 2020;14:78-85. https://doi.org/10.1037/ tep0000286.

21. Baingana F, Al'Absi M, Becker AE, Pringle B. Global research challenges and opportunities for mental health and substance-use disorders. Nature. 2015;527:S172-7. https://doi.org/10.1038/nature16032

22. Myers B, Petersen Z, Kader R, Parry CDH. Moving beyond access. Towards a quality-oriented substance abuse treatment system in South Africa. South Afr Med J. 2012;102(8):667-8. https://doi.org/10.7196/samj.5990.

23. Tran BX, Moir M, Latkin CA, Hall B, Nguyen NB, Ha GH, et al. Global research mapping of substance use disorder and treatment 1971-2017: implications for priority setting. Subst Abuse Treat Prev Policy. 2019;14:21. https://doi.org/10.1186/s13011-019-0204-7.

24. Degenhardt L, Glantz M, Evans-Lacko S, Sadikova E, Sampson N, Thornicroft $\mathrm{G}$, et al. Estimating treatment coverage for people with substance use disorders: an analysis of data from the World Mental Health Surveys World Psychiatry. 2017;16:299-307. https://doi.org/10.1002/wps.20457.

25. Myers B, Carney T, Wechsberg WM. "Not on the agenda": a qualitative study of influences on health services use among poor young women who use drugs in Cape Town, South Africa. Int J Drug Policy. 2016:30:52-8.

26. Magidson JF, Joska JA, Regenauer KS, Satinsky E, Andersen LS, SeitzBrown CJ, et al. "Someone who is in this thing that I am suffering from": The role of peers and other facilitators for task sharing substance use treatment in South African HIV care. Int J Drug Policy. 2019;70:61-9. https://doi.org/10.1016/j.drugpo.2018.11.004.

27. Reed E, Emanuael AN, Myers B, Johnson K, Wechsberg WM. The relevance of social contexts and social action in reducing substance use and victimization among women participating in an HIV prevention intervention in Cape Town, South Africa. Subst Abuse Rehabil. 2013;4:55-64. https:// doi.org/10.2147/SAR.S45961.

28. Parry CDH, Bhana A, Plüddemann A, Myers B, Siegfried N, Morojele NK, et al. The South African community epidemiology network on drug use (SACENDU): description, findings (1997-1999), and policy implications. Addiction. 2002;97:969-76. https://doi.org/10.1046/j.1360-0443.2002. 00145.x.

29. Myers B, Burnhams NH, Fakier N. Monitoring and evaluation of substance abuse services in South Africa: implications for policy and practice. Int J Ment Heal Addict. 2010;8:557-65. https://doi.org/10.1007/ s11469-009-9232-2. 
30. Myers B, Johnson K, Lucas W, Govender R, Manderscheid R, Williams PP, et al. South African service users' perceptions of patient-reported outcome and experience measures for adolescent substance use treatment: a qualitative study. Drug Alcohol Rev. 2019;38:823-30. https://doi.org/10. 1111/dar.12996.

31. Hinsley K, Kelly PJ, Davis E. Experiences of patient-centred care in alcohol and other drug treatment settings: a qualitative study to inform design of a patient-reported experience measure. Drug Alcohol Rev. 2019;38(6):664-73. https://doi.org/10.1111/dar.12965.

32. Kuusisto K, Lintonen T. Factors predicting satisfaction in outpatient substance abuse treatment: a prospective follow-up study. Subst Abuse Treat Prev Policy. 2020;15(1):35. https://doi.org/10.1186/s13011-020-00275-5.

33. Myers B, Williams PP, Govender R, Manderscheid R, Koch JR. Substance abuse treatment engagement, completion and short-term outcomes in the Western Cape Province, South Africa: findings from the service quality measures initiative. Drug Alcohol Depend. 2018;185:278-84. https://doi. org/10.1016/j.drugalcdep.2017.12.033.

34. Neale J, Vitoratou S, Finch E, Lennon P, Mitcheson L, Panebianco D, et al. Development and validation of "SURE": a patient reported outcome measure (PROM) for recovery from drug and alcohol dependence. Drug Alcohol Depend. 2016;165:159-67. https://doi.org/10.1016/j.drugalcdep. 2016.06.006.

35. Wiering B, de Boer D, Delnoij D. Patient involvement in the development of patient-reported outcome measures: a scoping review. Health Expect. 2017;20(1):11-23. https://doi.org/10.1111/hex.12442.

36. Haugum M, Iversen HH, Bjertnaes $\mathrm{O}$, Lindahl AK. Patient experiences questionnaire for interdisciplinary treatment for substance dependence (PEQ-ITSD): reliability and validity following a national survey in Norway. BMC Psychiatry. 2017;17(1):73. https://doi.org/10.1186/ s12888-017-1242-1.

37. Pilkonis $\mathrm{PA}$, Yu L, Dodds $\mathrm{NE}$, Johnston $\mathrm{KL}$, Lawrence $\mathrm{SM}$, Hilton TF, et al. Item banks for substance use from the patient-reported outcomes measurement information system (PROMIS $\left.\left({ }^{\circledR}\right)\right)$ : severity of use and positive appeal of use. Drug Alcohol Depend. 2015;156:184-92. https://doi.org/ 10.1016/j.drugalcdep.2015.09.008.

38. Myers B, Govender R, Koch JR, Manderscheid R, Johnson K, Parry CD Development and psychometric validation of a novel patient survey to assess perceived quality of substance abuse treatment in South Africa. Subst Abuse Treat Prev Policy. 2015;10:44. https://doi.org/10.1186/ s13011-015-0040-3.

39. Adamson SJ, Sellman JD, Frampton CMA. Patient predictors of alcohol treatment outcome: a systematic review. J Subst Abus Treat. 2009;36(1):75-86. https://doi.org/10.1016/j.jsat.2008.05.007.

40. Haugum M, Iversen $\mathrm{HH}$, Helgeland J, Lindahl AK, Bjertnaes O. Patient experiences with interdisciplinary treatment for substance dependence: an assessment of quality indicators based on two national surveys in Norway. Patient Prefer Adherence. 2019;13:453-64. https://doi.org/10. 2147/PPA.S194925.

41. Myers B, Williams PP, Govender R, Manderscheid R, Koch JR. A mixedmethods evaluation of the implementation of a performance measurement system for South Africa's substance use treatment services. J Stud Alcohol Drugs. 2019. https://doi.org/10.15288/jsads.2019.s18.131.

42. Myers B, Petersen Z, Kader R, Koch JR, Manderscheid R, Govender R, et al. Identifying perceived barriers to monitoring service quality among substance abuse treatment providers in South Africa. BMC Psychiatry. 2014;14:31. https://doi.org/10.1186/1471-244X-14-31.

43. Myers B, Govender R, Manderscheid R, Petersen-Williams P, Johnson K, Koch JR. Need for and readiness to implement a performance measurement system for South Africa's substance abuse treatment services. Int Ment Health Addict. 2016;15:795-800. https://doi.org/10.1007/s1146901609706-y.

44. Myers B, Williams PP, Johnson K, Govender R, Manderscheid R, Koch JR. Providers' perceptions of the implementation of a performance measurement system for substance abuse treatment: a process evaluation of the Service Quality Measures initiative. South Afr Med J. 2016;106:308-11.

45. Myers B, Petersen-Williams P, Johnson K, Govender R, Manderscheid R, Koch R. Readiness to adopt a performance measurement system for substance abuse treatment: findings from the service quality measures initiative. South Afr Med J. 2017;107:160-4.
46. Myers B. Barriers to alcohol and other drug treatment use among Black African and Coloured South Africans. BMC Health Serv Res. 2013;17:177. https://doi.org/10.1186/1472-6963-13-177.

47. Kour P, Lien L, Kumar B, Biong S, Pettersen H. Treatment experiences with Norwegian health care among immigrant men living with cOoccurring substance use- and mental health disorders. Subst Abuse. 2020;14:1178221820970929. https://doi.org/10.1177/1178221820970929.

48. Mays VM, Jones AL, Delany-Brumsey A, Coles C, Cochran SD. Perceived discrimination in health care and mental health/substance abuse treatment among blacks, latinos, and whites. Med Care. 2017;55(2):173-81. https://doi.org/10.1097/M]LR.0000000000000638.

49. Moll T. Medical mistrust and enduring racism in South Africa. Bioeth Inq. 2021. https://doi.org/10.1007/s11673-020-10072-1.

50. Myers B, Fakier N. Provision of mental health services in South African substance abuse treatment facilities. Int J Ment Health Addict. 2009:7:441-9.

51. Myers B, Carney T, Johnson K, Browne A, Wechsberg WM. Service providers' perceptions of barriers to the implementation of trauma-focused substance use services for women in Cape Town, South Africa. Int J Drug Policy. 2020;75: 102628. https://doi.org/10.1016/j.drugpo.2019.102628.

52. Goldstone D, Bantjes J, Dannatt L. Mental health care providers'suggestions for suicide prevention among people with substance use disorders in South Africa: a qualitative study. Subst Abuse Treat Prev Policy. 2018;13:47. https://doi.org/10.1186/s13011-018-0185-y.

53. Sorsdahl K, Naledi T, Lund C, Levitt NS, Joska JA, Stein DJ, Myers B. Integration of mental health counselling into chronic disease services at the primary health care level: formative research on dedicated versus designated strategies in the Western Cape, South Africa. J Health Serv Res Policy. 2021;26(3):149-50. https://doi.org/10.1177/1355819620954232.

54. Saban A, Flisher AJ, Grimsrud A, Morojele N, London L, Williams DR, Stein DJ. The association between substance use and common mental disorders in young adults: results from the South African Stress and Health (SASH) Survey. Pan Afr Med J. 2014;17(Suppl 1):11. https://doi.org/10. 11694/pamj.supp.2014.17.1.3328.

55. Watt MH, Myers B, Towe SL, Meade CS. The mental health experiences and needs of methamphetamine users in Cape Town: a mixed-methods study. South Afr Med J. 2015;105(8):685-8. https://doi.org/10.7196/SAMJn ew.7910.

56. Myers B, Carney T, Browne FA, Wechsberg WM. A trauma-informed substance use and sexual risk reduction intervention for young South African women: a mixed-methods feasibility study. BMJ Open. 2019;9: 024776. https://doi.org/10.1136/bmjopen-2018-024776.

57. Myers B, Lund C, Lombard C, et al. Comparing dedicated and designated models of integrating mental health into chronic disease care: study protocol for a cluster randomized controlled trial. Trials. 2018;19:185. https:// doi.org/10.1186/s13063-018-2568-9.

58. Singla DR, Kohrt BA, Murray LK, Anand A, Chorpita BF, Patel V. Psychological treatments for the world: lessons from low- and middle-income countries. Annu Rev Clin Psychol. 2017;13:149-81. https://doi.org/10. 1146/annurev-clinpsy-032816-045217.

59. Jacobs Y, Myers B, van der Westhuizen C, Brooke-Sumner C, Sorsdahl K. Task sharing or task dumping: counsellors experiences of delivering a psychosocial intervention for mental health problems in South Africa. Commun Mental Health J. 2021;57:1082-93. https://doi.org/10.1007/ s10597-020-00734-0.

60. Petersen Williams P, Brooke-Sumner C, Joska J, Kruger J, Vanleeuw L, Dada S, Sorsdahl K, Myers B. Young South African women on antiretroviral therapy perceptions of a psychological counselling program to reduce heavy drinking and depression. Int J Environ Res Public Health. 2020;17:2249. https://doi.org/10.3390/ijerph17072249.

\section{Publisher's Note}

Springer Nature remains neutral with regard to jurisdictional claims in published maps and institutional affiliations. 